
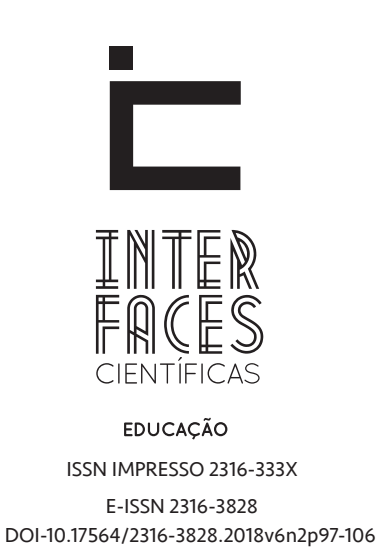

\title{
A INSTRUCÇ̃̃O É A MAIS SOLIDA BASE D'UMA SOCIEDADE BEM ORGANIZADA: O ABONO DA CIVILIZAÇÃO. PROVÍNCIA DA PARAHYBA DO NORTE. 1849-1889
}

\author{
INSTRUCTION IS THE MOST SOLID BASIS IN A WELL-ORGANIZED SOCIETY: THE ALLOWANCE OF CIVILIZATION. PROVINCE OF \\ PARAHYBA DO NORTE. 1849-1889
}

LA INSTRUCCIÓN ES LA MÁS SOLIDA BASE DE UNA SOCIEDAD BIEN ORGANIZADA: EL ABONO DE LA CIVILIZACIÓN. PROVINCIA DE PARAHYBA DO NORTE. 1849-1889

Mauriceia Ananias ${ }^{2}$

\section{RESUMO}

Este artigo tem como objetivo apresentar o debate sobre a instrução e civilização na Província da Parahyba do Norte nos anos de 1849 a 1889 . Os dois primeiros regulamentos da instrução decretados após o Ato adicional à constituição de 1824 marcam o começo da narrativa. O final do estudo indica o ocaso da monarquia e a reconfiguração em outro regime político, marcando a sociedade e o ensino. Os estudos no campo da história da educação no período imperial têm demonstrado que a ideia de instruir estava relacionada à necessidade de inserir a população em um projeto civilizatório. O percurso teórico-metodológico contemplou os estudos do sociólogo Nobert Elias para a conceituação do termo civilização. Para a análise, considerou-se que as elites da época reproduziram a ideia de civilizar como instrumento de controle e desenvolvimento da instrução de uma parcela da população pobre. Concluímos que, aos pobres, defenderam que a instrução os salvaria das trevas da ignorância. Pelas críticas, percebeu-se que havia uma vontade das pessoas em compor a forma escolar. Os conflitos indicaram dois movimentos: de um lado o controle, de outro a necessidade de socialização para reconhecimento público e moral. Os discursos dos homens da época defenderam o acesso à instrução como garantia de libertação dos povos, reconfigurando uma moral pautada no desenvolvimento material como forma de progresso social.

\section{PALAVRAS-CHAVE}

Parahyba do Norte. Província. Instrução Primária. Civilização. 


\section{ABSTRACT}

This article aims to present the debate on education and civilization in the Province of Parahyba do Norte, between the years 1849-1889. The first two instruction regulations enacted after the Additional Act to the Constitution of 1824 marks the beginning of the narrative. The study indicates the decline of the monarchy and a reconfiguration in another political regime inflecting in society and education. Studies in the field of history of education in the Imperial period have shown that the idea of "instruction" was related to the need to put people in a civilizing project. The theoretical and methodological approach included the sociologist Norbert Elias's studies for the definition of the term civilization. For the analysis, it was considered that the elites of the time reproduced the idea of civilizing as a control tool and development of a instruction to poor portions of the population. We conclude that to poor people was argued that education would save them from the darkness of ignorance. The criticism was realized that there was a willingness of people to compose a school form. Hence, conflicts indicated two movements: in one side control and on the other the need for socialization for public and moral recognition. The discourses and speeches of the men at that time defended the access to education as a guarantee of people liberation, reconfiguring a moral ruled material development as a form of social progress.

\section{KEYWORDS}

Province of Parahyba do Norte. Primary Instruction. Civilization.

\section{RESUMEN}

Este artículo tiene como objetivo presentar el debate sobre la instrucción y civilización en la Provincia de Parahyba del Norte en los años 1849 a 1889. Los dos primeros reglamentos de la instrucción decretados después del Acta adicional a la constitución de 1824 marcan el comienzo de la narrativa. El final del estudio indica el ocaso de la monarquía y la reconfiguración en otro régimen político marcando la sociedad y la enseñanza. Los estudios en el campo de la historia de la educación en el periodo imperial han demostrado que la idea de instruir estaba relacionada con la necesidad de insertar a la población en un proyecto civilizatorio. El recorrido teórico-metodológico contempló los estudios del sociólogo Nobert Elias para la conceptualización del término civilización. Para el análisis, se consideró que las élites de la época reprodujeron la idea de civilizar como instrumento de control y desarrollo de la instrucción de una parcela de la población pobre. Concluimos que, a los pobres, defendieron que la instrucción los salvaría de las tinieblas de la ignorancia. Por las críticas, se percibió que había una voluntad de las personas en componer la forma escolar. Los conflictos indicaron dos movimientos: por un lado el control, de otro la necesidad de socialización para reconocimiento público y moral. Los discursos de los hombres de la época defendieron el acceso a la instrucción como garantía de liberación de los pueblos, reconfigurando una moral pautada en el desarrollo material como forma de progreso social.

\section{PALABRAS CLAVE}

Provincia de Parahyba do Norte. Instrucción primaria. Civilización. 


\section{INTRODUÇÃO}

Os estudos realizados no campo da história da educação acerca do processo de institucionalização da instrução pública primária no período imperial brasileiro têm demonstrado que a ideia de instruir estava relacionada à necessidade de inserir a população em um projeto civilizatório. Os discursos dos homens da época defendiam o acesso à instrução como garantia de libertação dos povos das trevas da ignorância, reconfigurando uma moral pautada no desenvolvimento material como forma de progresso social, intencionando apresentar uma sociedade que se anunciava, apesar de todos os seus problemas, moderna. Pois, para esses homens, "[...] a ignorância era o mal do Império; as luzes da instrução, oferecidas por e para parcelas específicas da sociedade, salvariam a Nação" (ANANIAS, 2015, p. 13).

A narrativa convida os leitores para adentrar em um período de acaloradas discussões acerca da instrução, sua institucionalização e tentativa de uniformização, considerando um suposto modelo educativo que se acreditava seguir as orientações europeias e se difundia tendo como pressuposto as ideias de civilização e de desenvolvimento social. A história da educação paraibana seguiu o debate que as outras províncias travavam na retórica de uma educação como redentora de todos os males da Nação.

Assim, apresentamos as ideias de civilização e instrução defendidas pelos gestores entre os anos de 1849 a 1889. Para o primeiro período, destacamos os dois primeiros regulamentos da instrução decretados após o Ato adicional à Constituição do Império do Brasil de 1824. O final do estudo prenuncia o ocaso da monarquia e a reconfiguração em outro regime político, marcando a sociedade e o ensino.

A metodologia de análise considerou os discursos oficiais sobre a ideia de instrução primária e se empenhou em demonstrar a relação com a opinião, corrente à época, de civilização.

Os estudos em História da Educação indicam que os escritos do sociólogo alemão Norbert Elias (2011) são utilizados como referências para se conceituar a civilização e o processo civilizatório; a obra intitulada 0 processo civilizador, publicada em dois volumes, é recorrentemente citada como auxílio nesta empreitada.

Para Elias (2011, p. 24), “[...] civilização descreve um processo ou, pelo menos, seu resultado. Diz respeito a algo que está em movimento constante, movendo-se incessantemente para a frente". 0 contexto da análise do autor estava voltado para o continente Europeu e apresentava a ideia de civilização a partir de costumes que deveriam ser assumidos pela burguesia, copiando um modelo já estabelecido pela Corte francesa.

O Tratado de Erasmo foi utilizado para demonstrar, por exemplo, como se deveria portar-se à mesa para as refeições. Assim, “[...] se deu uma mordida no pão, não molhe novamente na travessa de uso comum. Camponeses podem fazer isso, mas não, gente fina" (ELIAS, 2011, p.74, grifos do autor). Acreditava-se que a civilização foi construída a partir de novos costumes que identificariam pessoas especiais, atualizadas e capazes de administrarem serviços e ocuparem cargos no universo de construção dos estados nacionais e das nações.

\begin{abstract}
A civilização que estamos acostumados a considerar como uma posse que aparentemente nos chega pronta e acabada, sem que perguntemos como viemos a possuí-la, é um processo ou parte de um processo em que nós todos estamos envolvidos. Todas as características distintivas que lhe atribuímos - a existência da maquinaria, descobertas científicas, formas de Estado, ou o que quer que seja - atestam a existência de uma estrutura particular de relações humanas, de uma estrutura social peculiar, e de correspondentes formas de comportamento. (ELIAS, 2011, p. 70).
\end{abstract}

A instrução foi compreendida como parte constituinte do ideal de civilização. Os discursos anunciavam as aulas primárias como necessárias a uma primeira (e talvez única) formação para a convivência e 
mão de obra que serviriam às elites na conformação dos espaços públicos - e privados - que a cogitada nova ordem pretendia.

0 cotejamento dos documentos da instrução primária que determinavam a criação, abertura e manutenção de cadeiras de primeiras letras, em especial tendo as leis como mediadoras de uma possível inteligibilidade, destacou a relação entre o que era anunciado e o que se esperava que vivessem à época.

Para além e aquém das leis, os relatórios dos presidentes de Província e os do diretor geral da instrução apresentavam propostas e medidas que previam o melhoramento da instrução e se tornaram fontes imprescindíveis para reconstruirmos os arranjos feitos na busca de se definir o papel e a importância da instrução, defendidos pelas elites para os chamados ignorantes de conhecimentos.

Para melhor compreensão da narrativa, considerando a introdução, dividimos o texto em três partes. No primeiro tópico, as informações sobre a sociedade e a instrução primária na Província da Parahyba do Norte foram apresentadas. No segundo, analisamos os discursos oficiais que indicaram que o conceito de civilização estava associado à defesa do desenvolvimento material e intelectual, tendo a instrução como medida de progresso social. E, por fim, apresentamos as considerações finais.

\section{SOCIEDADE E INSTRUÇÃO NA PROVÍ́NCIA DA PARAHYBA DO NORTE}

A instrução pública era defendida como principal ramo do serviço público nos discursos dos presidentes de Província e dos diretores da instrução como nos debates na Assembleia Legislativa. Estava fortemente ligada aos ideais de moralidade, ordem e prosperidade, aparecendo, constantemente, como causa e solução dos problemas enfrentados à época. 0 pressuposto pode ser observado na fala do Diretor Geral da Instrução, Manoel Porfirio Aranha:

\begin{abstract}
A instrucção é um poderoso elemento de moralidade, ordem e prosperidade publica, como é uma condição indispensavel de perfeição bem estar, e felicidade individual. E por tanto um beneficio de tão elevado alcance para a sociedade, não só deve ser largamente derramado por todos os membros d'ella; mas ainda é indispensavel que todos eles sejáo constrangidos a acceital-o, se por ventura não o fizerem expontaneamente. (PARAHYBA DO NORTE, Província. Relatório do Diretor Geral da Instrução..., 1861, p. 2).
\end{abstract}

A preocupação com a modernidade e civilização fazia parte de um projeto de Nação, envolvendo as principais cidades das províncias do Império e que perpassava, inclusive, o debate acerca da escravidão e os prejuízos que o legado do sistema escravagista poderia causar à sociedade.

Na Província da Parahyba do Norte, o reconhecimento do avanço de uma população livre em relação à escravizada não tardou a ocupar os relatórios dos presidentes da Província. No ano de 1846, Tenente Coronel Frederico Carneiro de Campos anunciou:

[...] vi muito amiudadas as habitações, residências de uma família mais ou menos numerosa e anfianço-vos também que não tenho encontrado em outra Província, das porque tenho descorrido, nem mais frequentes as casas e famílias, nem mesmo superior população livre. (PARAHYBA DO NORTE, Província. Relatório..., 1846, p. 6).

No ano de 1861, o presidente fez menção a um censo populacional realizado em 1852 mostrando que a quantidade da população escravizada sofreu uma queda:

Segundo o último senso, que teve lugar em 1852, onde a população da Provincia por 212,000 almas, das que 28,000 escravos. Tendo porém sido dizimada em 1856 pela cholera a população escrava, que, ainda por outras causas de todos conhecidas, tende a decrescer, creio que não será muito errado o calculo, que a limitar hoje a 20,000 almas, se tanto chegar”. (PARAHYBA DO NORTE, Província. Relatório..., 1861, p. 10).

O decréscimo da população escravizada era uma realidade na Parahyba e se juntava a uma mão de obra livre e pobre que se deslocava ou já vivia nas cidades e 
vilas. E, até passando por frequentes crises no mercado de açúcar e problemas na infraestrutura, de acordo com Rocha (2009), a economia continuava a se expandir com a criação de novos engenhos, como exemplo:

\begin{abstract}
Certamente, além da ampliação das áreas em que se produzia o açúcar, os indivíduos livres pobres devem ter sido fundamentais para o desenvolvimento dessas atividades agrícolas e de funções não-agrícolas da província, visto que eles, ao longo do Oitocentos, passaram a compor a maior parte da população, enquanto o número de escravos diminuía a cada década rumo ao fim da escravidão. (ROCHA, 2009, p.113).
\end{abstract}

Os documentos mostraram também uma preocupação dos presidentes da Província em relação à pobreza e condição de homens (e mulheres) pobres que habitavam as cidades e os espaços rurais. Pois, para eles, a pobreza era uma das causas dos crimes e agressões comumente vividos nas ruas e nas casas, como podemos observar no trecho do relatório do presidente da Província, Luiz Antonio da Silva Nunes, no ano de 1860:

Com efeito, nota se, ao menos aqui, que o maior numero das victimas saõ escolhidas por aquella espécie de delinquentes na classe das pessoas, que por sua pobresa e posição desvalida não dispõem dos necessários recursos para chamar o ofensor á juizo, e fase- lo punir na forma da lei, sendo que semelhante circumstancia, ao passo que acoroçoava o criminoso para a pratica do delicto, expunha o ofendido a misérrima posiçaõ d'aquelle, que, tendo o seo animal como único instrumento de trabalho, o que é aqui comum, via-se reduzido a naõ ter meio algum honesto de subsistência. (PARAHYBA DO NORTE, Província. Relatório..., 1860 , p. 6)

Assim, sem muito esforço, foi possível inferir que a população pobre era associada às causas de todos os males sociais. Na visão destes homens que detinham o poder e a força policial, a ordem deveria ser estabelecida. Para Abreu (2008, p.141), ao pesquisar sobre o uso do termo civilização pelas elites políticas, médicas, jurídicas, literárias e religiosas identificou que, no século XIX, estava imbricado à necessidade de dar civilidade às pessoas, e era entendida como “[...] 'cortesia', 'urbanidade', 'polidez’, ‘boa educação', ‘boas maneiras', 'delicadeza', 'etiqueta', ou seja, tudo que se opunha à rusticidade grosseira dos setores sociais mais baixos" (Aspas no original).

De acordo com a autora, existia, portanto, a vontade de se implementar na jovem Nação condições fundamentais para civilização de uma parcela da população que deveria produzir bens materiais, ser ordeira no trabalho, e, quase sempre, ser submissa na convivência social. Para tal, seria necessária uma política "[...] de controle da vadiagem e ociosidade da população livre e liberta pobre. Dentre as medidas adotadas, destacam-se aquelas ligadas a 'civilização dos costumes' da população, que precisava ser vigiada e disciplinada para o trabalho produtivo" (ABREU, 2008, p. 142, aspas no original).

As exigências se imbricavam: de um lado, a cobrança de se aplicar o discurso de civilizar uma parcela da população; de outro, a justificativa de se combater a violência. Ao final, o controle da população pobre aparecia como dever do governo provincial.

\section{A INSTRUÇ̃̃O PÚBLICA PRIMÁRIA: O ABONO DA CIVILIZAÇÃO}

No ano de 1849 a Província da Parahyba do Norte contava com 463 alunos distribuídos em 31 aulas de primeiras letras, os dados mostraram um aumento gradativo do número de alunos e aulas espalhadas pelas principais vilas e cidades, ainda que estas informações fossem passadas como negativas pelos presidentes da Província, pois diziam ser o número insuficiente e as aulas em funcionamento precárias. No ano de 1862 existiam 41 cadeiras para meninos e 15 para meninas em toda a Província, totalizando 1.766 alunos matriculados nas aulas/ cadeiras públicas primárias.

De acordo com o presidente Ambrozio Leitão da Cunha, no ano de 1859, o número de escolas e a frequência dos alunos não correspondiam ao número de habitantes, 
Existem actualmente na provincia 68 cadeiras do ensino primario, sendo 54 para o sexo masculino, e 14 para o femenino. D'aquellas estão providas interinamente 8 , e destas 2 . Todas as mais teem professores vitalicios. As primeiras forão frequentadas durante o segundo semestre do anno findo por 1:849 alumnos. As segundas por 279. Nem o numero das escolas, nem a sua frequencia me parece que correspondão devidamente á população da provincia, computada em 210:000. Hei de estudar devidamente este assumpto e providenciar convenientemente, ou reclamar de vós as medidas que não se incluiram nas minhas attribuições, ou nas authorizações que tendes dado á presidencia. No entretanto dizer-vos-ei já: Que tenho ouvido a pessoas competentes, e o confirma o director da instrução publica que a distribuição actual das cadeiras não é a melhor: pois que povoados há, onde serião ellas dispensaveis, entretanto que outros mais importantes estão privados d'aquelle beneficio. (PARAHYBA DO NORTE, Província. Relatório..., 1859, p. 11, grifos nossos).

O diretor geral da instrução Manoel Porfírio Aranha, em 1861, também afirmou a necessidade de aumentar o número de escolas primárias, a fim de alcançar as necessidades da Província:

O numero das cadeiras existentes não pode satisfazer as verdadeiras necessidades da Provincia. [...] E' pois manifesta a necessidade que ha de augmentar-se o numero de escolas do ensino primário. Não desconheço que se achão em má circumstancias as finanças da Provincia, mas entendo que as necessidades deste ramo de serviço, devem ser atendidas de preferencia as de qualquer outro, e que por amor delas é justo que se fação todos os possiveis sacrifícios. (PARAHYBA DO NORTE, Província. Relatório do diretor geral da instrução... 1861, p. 2).

No entanto, percebemos que existia uma distância considerável entre o discurso e a prática dos gestores quanto à instrução primária na Província. 0 que aparentemente seria uma preocupação - quanto ao número das cadeiras existentes e as ações para criação e manutenção das aulas -, se manifestava, muitas vezes, no fechamento de algumas cadeiras, alegando serem parcos os recursos, conforme determinou o presidente Francisco Araújo Lima:
Os recursos da Provincia não comportavam, e não comportam, o crescido numero de cadeiras de instrucção primaria, que existia: foi isto por Vós reconhecido assim e induz a crer a existencia da Lei $n^{0} 12$ de 8 de Agosto de 1860. Usando da autorização concedida no art. 4 da dita Lei por portaria de 18 de Junho ultimo, extingui as seguintes cadeiras: a 2. ${ }^{\text {a }}$ do bairro alto da capital, as de Tambaú, Cachoeira de Cebolas, Serra do Pontes, Cuité de Independencia, Araruna, Bethlem, S. João e S. José de Piranhas, Santa Luzia, Mulungú, Alagoa do Monteiro, Boa Vista, Pocinhos, e a de Fagundes; das quaes estavam providas vitaliciamente as de Mulungú e Santa Luzia, e sem titulo vitalico as de Fagundes, Alagoa do Monteiro, Pocinhos e Boa Vista. (PARAHYBA DO NORTE, Província. Relatório..., 1861, p. 6).

As ideias que Elias (2011) analisou como um processo para a história da Europa, em especial a França, foram apropriadas, anos depois, pelas elites brasileiras como ideal de sociedade a ser construída.

Para Carlota Boto, a ideia de civilização está relacionada às mudanças de costumes "[...] os saberes da escola constituem claramente uma forma de civilizar. O conceito de civilização traz implícita a suposição de superioridade de uma cultura sobre as outras" (BOTO, 2010, p. 35).

Assim, defendeu que a escola moderna assumiu, por excelência, a guarda do ensino da civilização, a partir do momento em que

[...] terá a marca de tal matriz civilizadora. A escola que ensina o ler, escrever e contar pretende, acima de tudo, civilizar - ou seja, conferir prioridade à transmissão sistemática e institucional de formas de se comportar. Tornar civilizada uma sociedade supõe ampliar sistematicamente o raio da racionalidade no trato. Abrandam-se as maneiras, criam-se sutilezas para o intercâmbio social, oferece-se um padrão de conduta de distinção, ao qual serão opostos como bárbaros todos os comportamentos divergentes. (BOTO, 2010, p.47).

0 acesso à instrução era compreendido como uma garantia de que os governos estavam atendendo aos pedidos da época. A defesa retomava, em especial, os ideais iluministas que proclamaram a libertação dos povos da ignorância numa lógica simplista que associava, quase que mecanicamente, o desenvolvimento material ao moral como forma de progresso social. A 
compreensão do conceito de civilização dos presidentes e diretores da instrução direcionava a instrução no atendimento destes propósitos.

Em nome de todos, desconsiderando as diferenças de origens econômica e social, propunham uma educação que parecia ser igualitária, mas que as condições das aulas, a contratação de professores e as verbas destinadas denunciaram, para a posteridade, tipos diferenciados de ensino. As reclamações dos professores por salas, por materiais de ensino e salários, a desqualificação da família como suporte da moral e dos chamados bons costumes, o repetitivo clamor por mais recursos foram analisados como elementos centrais que envolviam o emaranhado processo de escolarização da Província.

Apontavam-na como uma etapa da evolução, um melhoramento do homem que começaria pelas posturas individuais e deveria, gradativamente, atingir o nível das sociedades europeias. A instrução, para eles, organizada a partir da criação e manutenção das aulas, dos métodos de ensino, da disciplina e castigos, da frequência dos alunos e da postura e controle dos professores, deveria ser capaz de moldar a sociedade brasileira em direção ao progresso e ao desenvolvimento social.

Assim, compreendemos que à instrução era dada a responsabilidade para que o processo civilizatório, considerando as mudanças na sociedade, nas escolas e no comportamento e costumes da população, alcançasse o ideal de uma sociedade capaz de atender aos preceitos sociais e econômicos defendidos a partir de construções de bens materiais, como obras, estradas e bens intelectuais, como colégios, liceus e aulas de primeiras letras, referendando a civilização como o ápice do desenvolvimento material e moral de um país. Os discursos abalizaram o processo, sempre conflituoso, que fez com que estes homens acreditassem que deveriam ser os responsáveis por sua efetivação.

A instrucção publica é a questão social que mais importância tem merecido n'este século.

Depois de grandes e profundos estudos de notáveis pensadores os governos dos países civilisados comprehenderam que desenvolver a instrucção era abrir nova e larga senda para o progresso de seus paizes e pozeram-se a frente do movimento de modo que estou convencido de que o nosso século há de ser conhecido no fututo como o século da instrucção publica.

O Brasil não podia ficar indefferente n'este certamem de civilisação. 0 nosso pacto constitucional garante a instrucção gratuita a todos os cidadãos e promete-nos universidade que infelizmente ainda não temos. (PARAHYBA DO NORTE, Província. Relatório... 1882, p. 27).

Castanha (2007), ao relacionar o processo de instrução primária em Mato Grosso, relacionou à instrução a necessidade de disciplinar jovens e crianças para a sociedade, indicando que,

\begin{abstract}
A tarefa da instrução elementar estava muito clara, e o sucesso desse projeto dependia da ampliação e difusão desses princípios, entre a população livre, entre os livres pobres e mesmo entre os escravos. Cabia à instrução formar as crianças e jovens (futuros cidadãos - trabalhadores), disciplinando e preparando-os para desempenhar um certo papel social, bem como ocupar os espaços gerados a partir das novas relações de trabalho que estavam se concretizando. Portanto, a instrução elementar devia ser difundida de maneira adequada para todos os pontos possíveis do Império, pois, da humilde casa, que tinha o nome de escola, "dependia" o futuro de toda uma sociedade. (CASTANHA, 2007, p. 16).
\end{abstract}

Assim, a instrução passou a ser reconhecida como um problema social, pois retiraria do "torpor" e do "estado perigoso" que os "cidadãos" estavam: causa, caminho e resultado do conhecimento que levaria à tão propalada prosperidade da Província e do país (PARAHYBA DO NORTE, Província. Relatório... 1882, p. 27).

A defesa da gratuidade se estendida retoricamente a todos. A criação de medidas que obrigassem os pais a enviarem os filhos às aulas perpassava a necessidade do fornecimento de materiais aos meninos pobres. A ação do Governo provincial indicava a legislação como caminho para a obrigatoriedade adoção de medidas, da mesma forma, a lacuna - falta de materiais - reforçou o nosso argumento de que os meninos pobres, desvalidos de fortuna, frequentavam as aulas. Para além das supostas ações, subtendemos que aos professores caberia a responsabilidade de prover e garantir no cotidiano, o que seria necessário para frequência dos alunos nas aulas públicas. 
Em 1861, ao sugerir mudanças à instrução primária paraibana, o Diretor Geral da instrução, Manoel Porfírio Aranha, defendeu que "[...] o ensino primario, deve[ria] ser levado mesmo á porta das familias, e que estas directa ou indirectamente deve[ria]m ser obrigadas a recebel-o, quando não queirão fazer voluntariamente". (PARAHYBA DO NORTE, Província. Relatório do diretor geral da instrução..., 1861, p. 3). À negligência das famílias vinculou-se a criação de meios para obrigá-las a dar instrução aos filhos, até se não pudessem ou quisessem.

Novamente, em 1865, a discussão foi retomada, por considerar que os países civilizados já adotavam a medida:

Nos paizes mais adiantados em civilisação, onde a instrucção popular tem adquirido a importancia que merece, o ensino é obrigatorio. Na Prussia impõe-se para esse fim penas severas; como bem-multas, prisões, trabaIhos e privações de soccorros publicos. Na Allemanha, e na Hollanda, graças a esses, e a outros meios efficazes, a instrucção se acha tão generalisada, que a ignorancia é considerada pelos habitos do povo como um vicio. É devido á esse systema de ensino obrigatorio que a Dinamarca deve a diffusão geral do ensino primario há mais de meio seculo. As Assembléas Provinciaes são em geral impotentes para decretarem medidas semelhantes: para isso é indispensavel a intervensão dos Poderes Geraes do Estado. (PARAHYBA DO NORTE, Província. Relatório do diretor geral da instrução..., 1865, p. 34, grifos nossos).

A instrução popular, no contexto estudado, foi entendida como a educação oferecida para todas as pessoas e necessária para o melhoramento da sociedade. As diferenças econômica, social e cultural não compunham as apreciações realizadas por aqueles que detinham o poder da escrita, nos documentos e da fala nos espaços públicos da época.

A instrução era:

[...] um poderoso elemento de moralidade, ordem e prosperidade publica, como é uma condição indispensavel de perfeição bem estar, e felicidade individual. E por tanto um beneficio de tão elevado alcance para a sociedade, não só deve ser largamente derramado por todos os membros d'ella; mas ainda é indispensavel que todos eles sejáo constrangidos a acceital-o, se por ventura não o fizerem expontaneamente. (PARAHYBA DA PARAHYBA, Província. Relatório do diretor da instrução..., 1861, p. 2).

\section{CONSIDERAÇÕES FINAIS}

A análise realizada, considerando a documentação, a metodologia e a orientação teórica, conduziu as conclusões de que os discursos demonstraram a defesa de uma educação para todos, numa retórica de benfeitoria e benemerência aos mais pobres. Ao serem libertados da ignorância, colaborariam, sem revoltas, para a construção de Nação considerada ideal.

No discurso, as condições de acesso e permanência eram omitidas, pois todos passariam a ter a obrigação de irem à escola ou mandarem seus filhos frequentarem. Ao desconsiderar as diferenças, que, muitas vezes, permaneceram nas análises posteriores, aos menos críticos, fizeram crer, que no Brasil sempre houve elites, econômica e cultural, que se preocuparam com a educação do país, reforçando uma mentalidade de coesão e defesa da educação para todos, sem distinguir que os filhos destas elites frequentaram outras escolas e receberam saberes que os conduziram aos ensino secundário e superior para ocuparem cargos na máquina no Estado e na condução da administração das fortunas familiares.

A pesquisa realizada, apreciando, também, o aporte de outros trabalhos sobre a temática da instrução pública primária, concluiu que uma parcela da população pobre - identificada pelas origens, pela exclusão dos fóruns considerados privilegiados de cultura e pela negação do letramento -, foi alvo central de um tipo de ação que pretendia, além de controlá-la, inseri-la numa dinâmica social que a limitasse à instrução primária e à submissão de se contentar com sua posição na hierarquia da sociedade.

0 ideal superou a realidade e muitos dos homens pobres e seus filhos, passaram a acreditar que a escola poderia salvá-los das condições de inferioridade em que viviam. As elites, ao defenderem a instrução tinham, como demonstrado, um modelo de civilização que perpassava a forma de gerir a máquina estatal, seus negócios e ideias para controlar e acomodar a sociedade. 


\section{REFERÊNCIAS}

ABREU, Martha. Civilização. In: VAINFAS, Ronaldo (Org.). Dicionário do Brasil imperial. Rio de Janeiro: Objetiva, 2008.

\section{ANANIAS, Mauricéia. As escolas para pobres:}

instrução, trabalho e civilização: Campinas-SP, 18601889. João Pessoa: UFPB, 2015.

BOTO, Carlota. A racionalidade escolar como processo civilizador: a moral que captura almas. Revista Portuguesa de Educação, Universidade do Minho, Braga, Portugal, v.23, n.2, 2010.

CASTANHA, André Paulo. Pedagogia da Moralidade: a ordem civilizatória imperial. Revista Piquiriguaçu, Cascavel-PA, p. 14-15, 20 maio 2007.

ELIAS, Nobert, $\mathbf{O}$ processo civilizador. V.1. 2.ed. Rio de Janeiro: Zahar, 2011.

PARAHYBA DO NORTE, Província. Relatório apresentado a Assembleia Legislativa Provincial da Parahyba do Norte pelo presidente da mesma Província, o tenente coronel, Frederico Carneiro de Campos, em Maio de 1846. Pernambuco, Typ. Imparcial, 1846. Disponível em: <http://www.crl.edu/pt-br/brazil/about-project>. Acesso em: 18 jun. 2015.

PARAHYBA DO NORTE, Província. Relatório apresentado a Assembleia Legislativa da Parahyba do Norte pelo Presidente da Província, o Dr. Ambrozio Leitão da Cunha, em 2 de Agosto de 1859. Parahyba, Typ. de José Rodrigues da Costa, 1859. Disponível em: <http://www.crl.edu/pt-br/brazil/about-project $>$. Acesso em: 18 jun. 2015.

PARAHYBA DO NORTE, Província. Relatório apresentado a Assembleia Legislativa da
Província da Parahyba do Norte em 15 de Junho de 1860 pelo presidente, Dr. Luiz Antonio da Silva Nunes. Parahyba, Typ. de José Rodrigues da Costa, 1860. Disponível em: <http://www.crl.edu/ pt-br/brazil/about-project>. Acesso em: 18 jun. 2015.

PARAHYBA DO NORTE, Província. Relatório apresentado a Assembleia Legislativa Provincial da Parahyba do Norte pelo Exm. Sr. Dr. Francisco Araujo Lima na abertura da sessão ordinária de 1863. Parahyba, Typ. Parahybana, [n.d.]. Disponível

PARAHYBA DO NORTE, Província. Relatório apresentado a Assembleia Legislativa Provincial da Parahyba do Norte pelo Presidente, Exm. Sr. Dr. Manoel Ventura de Barros Leite Sampaio, em 4 de Outubro de 1882. Parahyba, Typ. do Commercio, 1882. Disponível em: <http://www. crl.edu/pt-br/brazil/about-project>. Acesso em: 18 jun. 2015.

PINHEIRO, Antonio Carlos Ferreira; CURY, Cláudia Engler (Org.). Leis e Regulamentos da Instrução Pública no Período Imperial. Coleção Documentos da Educação Brasileira [recurso eletrônico] - Dados eletrônicos - Brasília: Instituto Nacional de Estudos e Pesquisas Educacionais Anísio Teixeira, 2004.

ROCHA, Solange Pereira da. Gente negra na Paraíba oitocentista: população, família e parentesco espiritual. São Paulo: UNESP, 2009.

SÁ, Ariane Norma de Menezes. Escravos, libertos e insurgentes: Paraíba (1850-1888). 2.ed. João Pessoa: UFPB, 2005. 
1 Doutoranda em Educação do Programa de Pós-Graduação em Educação da Universidade Federal da Paraíba, na linha de História da Educação, com ênfase para pesquisa da escolarização da população pobre e negra no século XIX. Mestrado em Educação. Graduação em Pedagogia. E-mail: lays.regin@ gmail.com

2 Professora Associada do Centro de Educação e membro do Programa de Pós-graduação em Educação da Universidade Federal da Paraíba. Possui graduação em Licenciatura Plena em Filosofia pela Pontifícia Universidade Católica de Campinas - PUCC - (1994), mestrado em História da Educação pela Universidade Estadual de Campinas - UNICAMP- (2000) e doutorado em História da Educação pela Universidade Estadual de Campinas - UNICAMP- (2005). Compõe a Comissão Editorial da Revista HISTEDBR On-line UNICAMP/SP. Integra os Grupos de pesquisa: História da Educação no Nordeste Oitocentista- GHENO e Estudos e Pesquisas História da Educação da Paraíba- HISTEDBR/PB, ambos radicados na Universidade Federal da Paraíba e registrados no Diretório de Grupos do CNPQ. Tem experiência na área de Educação, com ênfase em História da Educação, atuando principalmente com temas relacionados à história da educação na Paraíba Imperial, em especial, pesquisando processos de escolarização e a institucionalização da escola pública primária.E-mail: mauriceia.ananias@gmail.com 